Int. J. Electrochem. Sci., 16 (2021) Article ID: 21044

\title{
Jet Pulse Electrodeposited Ni-SiC Thin Coatings by Using Experimental System Designed for Potential Industrial Application
}

\author{
Wenqing Liu ${ }^{1}$, Kedi Jiang ${ }^{1, *}$, Qiang Li ${ }^{1,2}$, Chunyang Ma ${ }^{1}$, Fafeng Xia ${ }^{1}$ \\ ${ }^{1}$ College of Mechanical Science and Engineering, Northeast Petroleum University, Daqing 163318, PR \\ China; \\ ${ }^{2}$ School of Chemistry Engineering, Hanshan Normal University, Chaozhou 521041, China \\ *E-mail: chunyangandma@163.com
}

doi: $10.20964 / 2021.04 .23$

Received: 3 December 2020 / Accepted: 21 January 2021 / Published: 28 February 2021

\begin{abstract}
$\mathrm{Ni}-\mathrm{SiC}$ thin coatings were prepared by using the jet pulse electrodeposition (JPED) method while the jet rate was determined with the Fluent software. Moreover, the effects of jet rate on the surface topography, microstructure, surface hardness, and wear property of the Ni-SiC thin coatings were examined through scanning electron microscopy (SEM), scanning probe microscopy (SPM), transmission electron microscopy (TEM), X-ray diffraction (XRD), Vickers hardness instrument, and abrasion testing machine. The $\mathrm{SiC}$ particles revealed diffraction peaks at $34.1^{\circ}, 41.4^{\circ}$, and $59.6^{\circ}$,

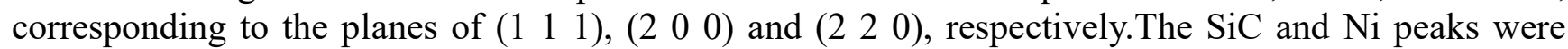
observed at $19.5 \mathrm{~nm}$ and $50.2 \mathrm{~nm}$, respectively, in the prepared $\mathrm{Ni}-\mathrm{SiC}$ thin coatings at $3 \mathrm{~m} / \mathrm{s}$ jet rate. Furthermore, it also exhibited significantly larger microhardness value i.e. $886.65 \mathrm{HV}$ as compared to the Ni-SiC coating obtained at $1 \mathrm{~m} / \mathrm{s}$ i.e. $730.15 \mathrm{HV}$. There were certain scratches and slight small-sized pits in the coating surface prepared at $3 \mathrm{~m} / \mathrm{s}$. In addition, the Ni-SiC thin coating deposited at $3 \mathrm{~m} / \mathrm{s}$ processed the highest impedance, indicating the best corrosion resistance among all coatings.
\end{abstract}

Keywords: Ni-SiC thin coating; jet rate; surface topography; abrasion testing; surface hardness

\section{FULL TEXT}

(C) 2021 The Authors. Published by ESG (www.electrochemsci.org). This article is an open access article distributed under the terms and conditions of the Creative Commons Attribution license (http://creativecommons.org/licenses/by/4.0/). 